Aim of the study: Herein, this meta-analysis study evaluated the efficacy of palifermin after HSCT on the incidence and severity of OM or aGVHD in hematologic malignancy patients in randomized clinical trials (RCTs).

Materials and methods: To compare the efficacy of palifermin on adverse events, OM and aGVHD compared with placebo, we searched databases of PubMed/Medline, Web of Science and Cochrane Library for RCTs based on a number of criteria.

Results: There was no difference observed in the incidence of $\mathrm{OM}$ and aGVHD between two groups. The subgroup analysis didn't show significant differences in two groups for aGVHD grade $2-4$ (odds ratio $[\mathrm{OR}]=1.54,95 \%$ confidence interval (CI): 0.70-3.39, $p=$ $0.28)$, aGVHD grade $3-4(\mathrm{OR}=0.97$ $95 \% \mathrm{Cl}: 0.48-1.94, \mathrm{p}=0.92)$, OM grade 2-4 (OR $=0.76,95 \% \mathrm{Cl}: 0.42-1.38, p=$ $0.37)$ and $\mathrm{OM}$ grade $3-4(\mathrm{OR}=0.54$, $95 \% \mathrm{Cl}: 0.25-1.15, p=0.11$ ], but erythe$\mathrm{ma}$ as an adverse effect in palifermin group was higher than placebo group $(\mathrm{OR}=1.86,95 \% \mathrm{Cl}: 1.10-3.15, p=0.02]$ Conclusions: This meta-analysis of six clinical trials found no statistically significant difference in OM and aGVHD grades in patients receiving $60 \mu \mathrm{g} /$ $\mathrm{kg} /$ day dose of palifermin compared with those receiving a placebo. However, oral mucosal erythema was more prevalent among patients receiving palifermin than patients receiving a placebo.

Key words: palifermin, hematopoietic cell transplantation, hematology malignancy, adverse event, meta-analysis.

Contemp Oncol (Pozn) 2017; 21 (4): 299-305 DOI: https://doi.org/10.5114/wo.2017.72400

\section{Efficacy of palifermin on oral mucositis and acute GVHD after hematopoietic stem cell transplantation (HSCT) in hematology malignancy patients: a meta-analysis of trials}

\author{
Hamid Reza Mozaffari ${ }^{1,2}$, Mehrdad Payandeh ${ }^{3}$, Mazaher Ramezani ${ }^{4}$, \\ Masoud Sadeghi ${ }^{2,5}$, Mohammad Mahmoudiahmadabadi ${ }^{2}$, Roohollah Sharifi ${ }^{6}$ \\ ${ }^{1}$ Department of Oral and Maxillofacial Medicine, School of Dentistry, Kermanshah \\ University of Medical Sciences, Kermanshah, Iran \\ ${ }^{2}$ Medical Biology Research Center, Kermanshah University of Medical Sciences, \\ Kermanshah, Iran \\ ${ }^{3}$ Department of Hematology and Medical Oncology, Kermanshah University of Medical \\ Sciences, Kermanshah, Iran \\ ${ }^{4}$ Molecular Pathology Research Center, Emam Reza Hospital, Kermanshah University \\ of Medical Sciences, Kermanshah, Iran \\ ${ }^{5}$ Students Research Committee, Kermanshah University of Medical Sciences, \\ Kermanshah, Iran \\ ${ }^{6}$ Department of Endodontics, School of Dentistry, Kermanshah University of Medical \\ Sciences, Kermanshah, Iran
}

\section{Introduction}

Hematopoietic stem cell transplantation (HSCT) is a potentially curative therapeutic procedure for patients with relapsed or refractory hematological malignancies (HMs) [1]. Mucositis is a major factor contributing to morbidity and mortality in patients undergoing HSCT, commonly developing after radiation-based conditioning regimens [2,3]. The overall incidence of mucositis in HSCT is usually reported to be between 75 and 99\% [4]. Oral mucositis $(\mathrm{OM})$ remains one of the most significant complications of high-dose chemotherapy and HSCT [5]. The OM is an inflammation of the mucous that is characterized by color alteration, atrophy, ulceration, edema, and alteration of the local perfusion [6, 7]. Palifermin is a recombinant human keratinocyte growth factor (KGF) which is known to stimulate the growth of epithelial cells in a wide variety of tissues [8]. Palifermin has been shown as a cost-effective therapy in an analysis using the Spanish healthcare system [9]. In addition to, palifermin can affect on GVHD in the HM patients after HSCT [3]. The aim of this meta-analysis study was to assess the efficacy of palifermin after HSCT on the incidence and severity of OM or acute graft-versus-host disease (aGVHD) in HM patients in randomized clinical trials (RCTs).

\section{Materials and methods}

Search strategies

We conducted a comprehensive search with search terms included with palifermin and hematopoietic stem cell transplantation or HSCT or stemcell transplant or stem cell transplant or hematopoietic cell transplantation or HCT or hematopoietic stem cell transplant or stem cell transplantation or stem-cell transplantation or hematopoietic stem-cell transplantation and oral mucositis or mucositis in databases of PubMed/Medline, Web of Sci- 
ence and Cochrane Library from Jan 1991 to 24 $4^{\text {th }}$ Nov 2016 for English-language publications.

\section{Study selection}

Three authors evaluated the selection of the studies. The first author (M.S) conducted the search and applied the selection criteria and then M.R confirmed the selection from the overall search results. If there was any disagreement between the two authors, the third author (H.R.M) resolved the problem. All the articles of this study were examined for assessment of the efficacy of palifermin after HSCT in HM patients compared with placebo. Studies in this meta-analysis had to include the following inclusion criteria: a) the clinical trial with two arms (palifermin and placebo groups); b) the human studies; c) the comparison of GVHD and/or OM based on the World Health Organization (WHO) in two groups after HSCT; d) the studies reporting adverse events in two groups undergoing HSCT. Exclusion criteria: a) duplication of previous publications; b) the review, case report, case series, case-control and retrospective studies; c) the trial without placebo group; d) the trial without complete information about $\mathrm{OM}$ and/or GVHD; e) the trial reporting solid tumor.

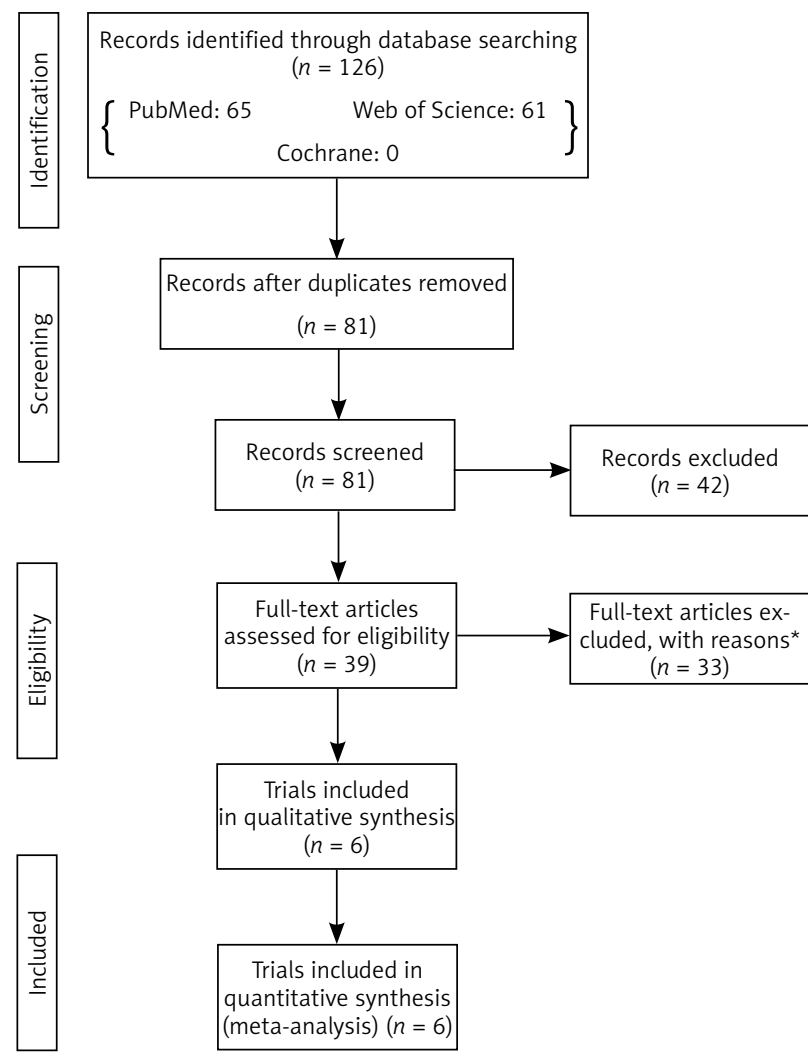

* 15 studies were case control/cohort, 1 was animal study; 1 case series study; 2 observational studies without placebo group; 2 retrospective studies; 3 review studies; 1 case report study; 2 trials had no complete information for oral mucositis or GVHD; 2 trials reported OM in solid tumor patients, 1 trial didn't report OM after induction chemotherapy, not SCT, 1 study was retrospective study

Fig. 1. Flow diagram

\section{Data extraction}

The name of author, year of publication, country of the region, the number of patients in each palifermin group, the number of patients in each placebo group, the dose of palifermin and the type of HSCT was collected for each study that met our criteria. The incidence and severity of OM, aGVHD and adverse events included in the studies were reported. OM was assessed using the WHO toxicity scale. Adverse events were assessed during the study period and graded according to the WHO and National Cancer Institute Common Toxicity Criteria ( $\mathrm{NCl}-\mathrm{CTC}$ ) toxicities scale. Severity of GVHD was determined clinically (physical examination and laboratory serum values), with biopsies of affected organs when available. Also, GVHD was graded weekly during the first 2 months after transplantation and then every other week to day 100 by specific observers according to consensus criteria that the study of Przepiorka et al. has used more descriptions [10].

\section{Quality evaluation}

Two authors (M.R and M.S) performed the quality of the studies using 13 criteria ${ }^{[1]}$ that these selected criteria were based on the guideline described by Fowkes and Fulton [12] for evaluating meta-analysis study effectively and a control for influence bias.

\section{Statistical analyses}

Analyses of data (a random-effect model) were used by Review Manager 5.3 (RevMan 5.3, The Cochrane Collaboration, Oxford, United Kingdom) using odds ratio (OR) and $95 \%$ confidence intervals (Cls). The heterogeneity between estimations was calculated by the $\mathrm{Q}$ and $\mathrm{I}^{2}$ statistics that for the $\mathrm{Q}$ statistic, heterogeneity was considered for $p<0.1$. The $\mathrm{I}^{2}$ statistic yields results ranging from 0 to $100 \%\left(1^{2}=0-25 \%\right.$, no heterogeneity; $I^{2}=25-50 \%$, moderate heterogeneity; $1^{2}=50-75 \%$, large heterogeneity; $\mathrm{I}^{2}=75-100 \%$, extreme heterogeneity) [13]. The publication bias was evaluated through funnel plot analysis with the Begg's and Egger's tests. P-value (2-tailed) $<0.05$ was considered in this meta-analysis statistically significant.

\section{Results}

\section{Study characteristics}

Out of 126 studies searched in databases, 39 studies were eligible for evaluation. Out of 33 studies, 6 trials reported the prevalence of GVHD and/or OM grades with adverse events in palifermin group compared with the placebo group after HSCT in HM patients that Fig. 1 shows the screening process of studies. The studies were reported between 2004 and 2016 that these 6 studies [14-19] included 419 patients in palifermin group and 316 patients in the placebo group (Table 1). The dose of palifermin was $60 \mu \mathrm{g} / \mathrm{kg} /$ day for all trials [15-19], except for one study [14] that doses were $40 \mu \mathrm{g} / \mathrm{kg} /$ day (cohort 1 only, 8 patients) or $60 \mu \mathrm{g} / \mathrm{kg} /$ day (all cohorts). Three studies $[14,16,18]$ reported the results in HM, one study [15] evaluated multiple myeloma (MM) and two other studies $[17,19]$ assessed acute lymphoblastic leukemia (ALL) patients. Three studies 
Table 1. The characteristics of meta-analysis studies $(n=6)$

\begin{tabular}{lccccc}
\hline Study (year) & Country & Cancer & Placebo Group $(N)$ & Palifermin Group (N) & Type of SCT \\
\hline Blazar et al. 2006 [14] & USA & HM & 31 & 69 & Allogeneic \\
Blijlevens et al. 2013 [15] & Netherlands & MM & 57 & $224^{*}$ & Autologous \\
Jagasia et al. 2012 [16] & USA & HM & 73 & 78 & Allogeneic \\
Lucchese et al. 2016 [17] & Italy & ALL & 27 & 27 & Autologous \\
Lucchese et al. $2016[19]$ & Italy & ALL & 22 & 24 & Allogeneic \\
Spielberger et al. 2004 [18] & USA & HM & 106 & 106 & Autologous
\end{tabular}

*115 patients randomized to pre-/post-high-dose Melphalan (HDM) and 109 patients randomized to pre-HDM.

HM - hematologic malignancy; MM - multiple myeloma; SCT - stem cell transplant, ALL - acute lymphoblastic leukemia

Table 2. Qualitative scoring of the included articles $(n=6)$

\begin{tabular}{|c|c|c|c|c|c|c|c|}
\hline Component & Definition & $\begin{array}{l}\text { Blazar } \\
\text { et al. [14] }\end{array}$ & $\begin{array}{l}\text { Blijlevens } \\
\text { et al. [15] }\end{array}$ & $\begin{array}{l}\text { Jagasia } \\
\text { et al. [16] }\end{array}$ & $\begin{array}{l}\text { Lucchese } \\
\text { et al. [17] }\end{array}$ & $\begin{array}{l}\text { Lucchese } \\
\text { et al. [19] }\end{array}$ & $\begin{array}{l}\text { Spielberger } \\
\text { et al. [18] }\end{array}$ \\
\hline 1. Study design & Description of study design & $E$ & $E$ & $E$ & $E$ & $E$ & $E$ \\
\hline \multirow[t]{2}{*}{ 2. Participants } & Eligibility criteria for participants & $E$ & $E$ & $E$ & $E$ & $E$ & $E$ \\
\hline & Entry criteria and exclusion & $E$ & $E$ & $E$ & $E$ & $E$ & $E$ \\
\hline \multirow[t]{2}{*}{ 3. Interventions } & Sufficient details & $E$ & $E$ & $E$ & $E$ & $E$ & $E$ \\
\hline & Description of modifier effects & $E$ & $E$ & $E$ & $E$ & $E$ & $E$ \\
\hline 4. Outcomes & Completely defined & $E$ & $E$ & $E$ & $E$ & $E$ & $E$ \\
\hline 5. Sample size & How sample size was determined & NE & $\mathrm{NE}$ & $\mathrm{NE}$ & $\mathrm{NE}$ & NE & NE \\
\hline 6. Randomization & Method used & $E$ & $E$ & $E$ & $E$ & $E$ & $\mathrm{E}$ \\
\hline 7. Blinding & Who was blinded and how & NE & $\mathrm{NE}$ & $\mathrm{NE}$ & $E$ & $E$ & $\mathrm{NE}$ \\
\hline $\begin{array}{l}\text { 8. Control group } \\
\text { acceptable }\end{array}$ & Definition of control & NE & NE & $\mathrm{NE}$ & $P$ & $P$ & $P$ \\
\hline \multirow[t]{2}{*}{ 9. Statistical methods } & Statistical methods used & $E$ & $E$ & $E$ & $E$ & $E$ & $E$ \\
\hline & Methods for additional analyses & $E$ & $E$ & $E$ & $E$ & $E$ & $E$ \\
\hline 10. Participant flow & For each group, losses and exclusions & $E$ & $E$ & $E$ & $E$ & $E$ & $E$ \\
\hline 11. Baseline data & Baseline clinical of each group & $E$ & E & $E$ & $E$ & $E$ & $E$ \\
\hline 12. Numbers analyzed & For each group & $E$ & $\mathrm{E}$ & $E$ & $E$ & $E$ & $E$ \\
\hline 13. Interpretation & Consistent with results & $E$ & $E$ & $E$ & $E$ & $E$ & $E$ \\
\hline
\end{tabular}

$N E$ - not explained; $E$ - explained; $P$ - partially

$[14,16,19]$ reported the results after allo-HSCT and three studies $[15,17,18]$ after auto-HSCT. One study [15] reported a total of 224 patients (115 patients randomized to pre-/ post-high-dose Melphalan (HDM) and 109 patients randomized to pre-HDM).

\section{Meta-analysis results}

The results of the pooled estimates of OM and aGVHD grades in two groups have been shown in Fig. 2. A random-effect model was used in all six trials. The subgroup analysis didn't show significant differences in two groups for aGVHD grade $2-4(\mathrm{OR}=1.54,95 \% \mathrm{Cl}: 0.70-3.39, p=$ $0.28)$, aGVHD grade $3-4(\mathrm{OR}=0.97,95 \% \mathrm{Cl}: 0.48-1.94$, $p=0.92)$, OM grade $2-4(\mathrm{OR}=0.76,95 \% \mathrm{Cl}: 0.42-1.38$, $p=0.37)$ and $\mathrm{OM}$ grade $3-4(\mathrm{OR}=0.54,95 \% \mathrm{Cl}: 0.25-1.15$, $p=0.11$. Also, heterogeneity for subgroups of aGVHD grade $2-4$, OM grade $2-4$ and OM grade 3-4 was moderate, large and extreme, respectively, but there was no heterogeneity for aGVHD grade 3-4.
The results of the pooled estimates of the prevalence of adverse events after HSCT have been shown in Fig. 3. The total analysis showed that there was a significant difference between two groups in total adverse events ( $O R=$ 1.15, 95\% Cl: 0.92-1.44, $p=0.20$ ) with large heterogeneity. The subgroup analysis showed that there were no significant differences between two groups for edema $(O R=1.28$, $95 \% \mathrm{Cl}: 0.80-2.05, p=0.31)$, rash $(\mathrm{OR}=1.23,95 \% \mathrm{Cl}: 0.67-$ $2.25, p=0.50]$, infection $(\mathrm{OR}=0.45,95 \% \mathrm{Cl}$ : $0.06-3.48$, $p=0.44)$, febrile neutropenia $(\mathrm{OR}=0.81,95 \% \mathrm{Cl}: 0.40-1.62$, $p=0.55)$, total parenteral nutrition $(\mathrm{OR}=1.09,95 \% \mathrm{Cl}$ : $0.49-2.43, p=0.83)$, cough $(\mathrm{OR}=1.23,95 \% \mathrm{Cl}: 0.80-1.88$, $p=0.35)$, pruritus $(\mathrm{OR}=0.75,95 \% \mathrm{Cl}: 0.28-2.00, p=0.57)$, taste alteration (OR $=1.01,95 \% \mathrm{Cl}: 0.30-3.36, p=0.99)$, white film coating tongue and mouth $(\mathrm{OR}=1.91,95 \% \mathrm{Cl}$ : $1.00-3.64, p=0.05)$, sensation of increased tongue thickness (OR $=1.72,95 \% \mathrm{Cl}: 0.80-3.69, p=0.16)$, taste loss (OR $=1.28,95 \% \mathrm{Cl}: 0.41-4.01, p=0.67)$ and paresthesia $(\mathrm{OR}=$ $3.45,95 \% \mathrm{Cl}: 0.79-15.14, p=0.10)$, but there was a signifi- 


\begin{tabular}{|c|c|c|c|c|c|c|}
\hline \multirow[b]{2}{*}{ Study of subgroup } & \multicolumn{2}{|c|}{ Palifermin } & \multicolumn{2}{|c|}{ Placebo } & \multirow[b]{2}{*}{ Weight } & \multirow{2}{*}{$\begin{array}{l}\text { Odds Ratio } \\
\text { M-H, Random, } 95\end{array}$} \\
\hline & \multicolumn{4}{|c|}{ 1.1.1. aGVHD grade $2-4$} & & \\
\hline Blazar et al. 2006 [14] & 17 & 69 & 8 & 31 & $5.9 \%$ & $0.94(0.36,2.49)$ \\
\hline Jagasia et al. 2012 [16] & 43 & 77 & 29 & 78 & $7.6 \%$ & $2.14(1.12,4.06)$ \\
\hline Subtotal $(95 \% \mathrm{Cl})$ & & 146 & & 109 & $13.5 \%$ & $1.54(0.70,3.39)$ \\
\hline Total events & 60 & & 37 & & & \\
\hline \multicolumn{7}{|c|}{$\begin{array}{l}\text { Heterogeneity: } \operatorname{Tau}^{2}=0.16, \chi^{2}=1.91, \mathrm{df}=4(p=0.17), I^{2}=48 \% \\
\text { Test for overall effect: } Z=1.08(p=0.28)\end{array}$} \\
\hline \multicolumn{7}{|l|}{ 1.1.2. aGVHD grade $3-4$} \\
\hline Blazar et al. 2006 [14] & 10 & 69 & 5 & 31 & $5.1 \%$ & $0.88(0.27,2.84)$ \\
\hline Jagasia et al. 2012 [16] & 12 & 77 & 12 & 78 & $6.4 \%$ & $1.02(0.43,2.42)$ \\
\hline Subtotal $(95 \% \mathrm{Cl})$ & & 146 & & 109 & $11.5 \%$ & $0.97(0.48,1.94)$ \\
\hline Total events & 22 & & 17 & & & \\
\hline \multicolumn{7}{|c|}{$\begin{array}{l}\text { Heterogeneity: } \operatorname{Tau}^{2}=0.00, \chi^{2}=0.04, \mathrm{df}=1(p=0.85), \mathrm{I}^{2}=0 \% \\
\text { Test for overall effect: } Z=0.10(p=0.92)\end{array}$} \\
\hline \multicolumn{7}{|l|}{ 1.1.3. Oral mucositis grade $2-4$} \\
\hline Blazar et al. 2006 [14] & 12 & 69 & 5 & 31 & $5.2 \%$ & $1.99(0.35,3.43)$ \\
\hline Blijjevens et al. 2013 Pre [15] & 56 & 109 & 33 & 57 & $7.6 \%$ & $0.77(0.40,1.47)$ \\
\hline Blijjevens et al. 2013 Pre/Post [15] & 79 & 115 & 33 & 57 & $7.5 \%$ & $1.60(0.83,3.08)$ \\
\hline Jagasia et al. 2012 [16] & 69 & 77 & 69 & 78 & $5.8 \%$ & $1.13(0.41,3.09)$ \\
\hline Lucchese et al. 2016 [17] & 12 & 27 & 18 & 27 & $5.4 \%$ & $0.40(0.13,1.21)$ \\
\hline Lucchese et al. 2016 [19] & 11 & 24 & 19 & 22 & $4.0 \%$ & $0.13(0.03,0.57)$ \\
\hline Subtotal $(95 \% \mathrm{Cl})$ & & 421 & & 109 & $35.4 \%$ & $0.76(0.42,1.38)$ \\
\hline Total events & 239 & & 17 & & & \\
\hline \multicolumn{7}{|c|}{$\begin{array}{l}\text { Heterogeneity: } \operatorname{Tau}^{2}=0.31, \chi^{2}=12.09, \mathrm{df}=5(p=0.03), \mathrm{I}^{2}=59 \% \\
\text { Test for overall effect: } Z=0.90(p=0.37)\end{array}$} \\
\hline \multicolumn{7}{|l|}{ 1.1.4. Oral mucositis grade $3-4$} \\
\hline Blazar et al. 2006 [14] & 10 & 69 & 5 & 31 & $5.2 \%$ & $0.88(0.27,2.84)$ \\
\hline Blijjevens et al. 2013 Pre [15] & 26 & 109 & 21 & 57 & $7.3 \%$ & $0.54(0.27,1.08)$ \\
\hline Blijjevens et al. 2013 Pre/Post [15] & 44 & 115 & 21 & 57 & $7.5 \%$ & $1.06(0.55,2.05)$ \\
\hline Jagasia et al. 2012 [16] & 62 & 77 & 57 & 78 & $7.0 \%$ & $1.52(0.72,3.24)$ \\
\hline Lucchese et al. 2016 [17] & 4 & 27 & 7 & 27 & $4.3 \%$ & $0.50(0.13,1.95)$ \\
\hline Lucchese et al. 2016 [19] & 4 & 24 & 7 & 22 & $4.2 \%$ & $0.43(0.11,1.74)$ \\
\hline Spielberger et al. 2004 [18] & 67 & 106 & 104 & 106 & $4.0 \%$ & $0.03(0.01,0.14)$ \\
\hline Subtotal $(95 \% \mathrm{Cl})$ & & 527 & & 378 & $39.5 \%$ & $0.54(0.25,1.15)$ \\
\hline Total events & 217 & & 17 & & & \\
\hline $\begin{array}{l}\text { Heterogeneity: } \text { Tau }^{2}=0.77, \chi^{2}=25 \\
\text { Test for overall effect: } Z=1.41(p=\end{array}$ & (16) $\mathrm{df}=6$ & $=0.0002$ & $I^{2}=66 \%$ & & & \\
\hline \multicolumn{2}{|l|}{ Total $(95 \% \mathrm{Cl})$} & 40 & \multicolumn{2}{|c|}{868} & $100 \%$ & $0.76(0.52,1.11)$ \\
\hline Total events & & & & & & \\
\hline \multicolumn{7}{|c|}{ Heterogeneity: $\operatorname{Tau}^{2}=0.40, \chi^{2}=46.42, \mathrm{df}=16(p=0.0001), \mathrm{I}^{2}=66 \%$} \\
\hline \multicolumn{7}{|c|}{$\begin{array}{l}\text { Test for overall effect: } Z=1.41(p=0.16) \\
\text { Test for subgroup differences: } \chi^{2}=3.84, \mathrm{df}=3(p=0.283), \mathrm{I}^{2}=21.9 \%\end{array}$} \\
\hline Test for subgroup differences: $\chi^{2}=$ & & & & & & \\
\hline
\end{tabular}

Fig. 2. Forest plot of oral mucositis and acute GVHD grades

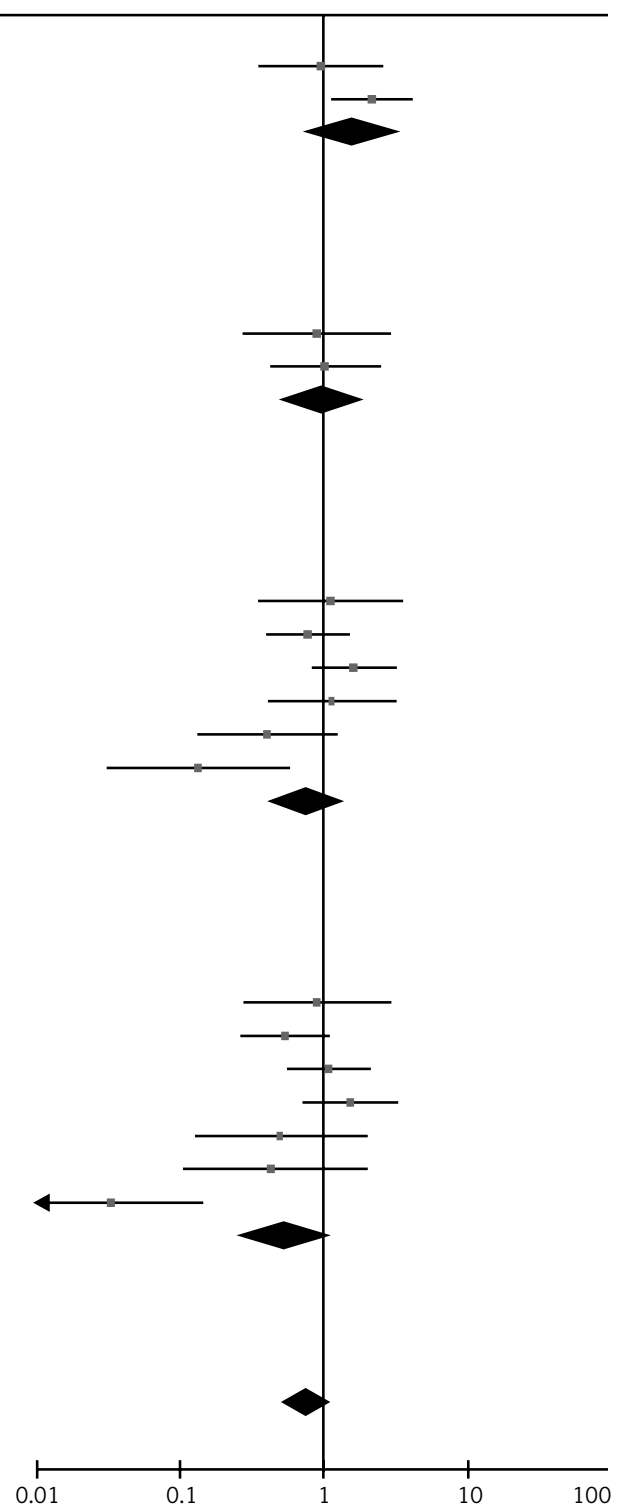

cant difference for erythema $(\mathrm{OR}=1.86,95 \% \mathrm{Cl}: 1.10-3.15$, $p=0.02$ ). The subgroup heterogeneity for adverse events is demonstrated in Fig. 3.

\section{Quality evaluation}

Table 2 shows the qualitative scoring of the included articles in meta-analysis. All studies [14-19] described the use of randomization, but none of them completely reported the sample size calculation. Two studies $[17,19]$ explained blinding. Three studies [14-16] describe fully the definition of controls, but three studies [17-19] partially.

\section{Publication bias}

The funnel plot analysis of random-effect of the studies in this meta-analysis has been shown in Fig. 4. The results of the Begg's and Egger's tests revealed that no publication biases existed in terms of OM grade $2-4$, OM grade 3-4 (Fig. 4A), infection, edema, rash, febrile neutropenia, total parenteral nutrition, cough, erythema, pruritus, white film coating tongue or mouth, sensation of increased tongue thickness and paresthesia (Fig. 4B). Regarding aGVHD grade 2-4, aGVHD grade 3-4 (Fig. 4A), Begg's and Egger's tests revealed no publication biases and could not be performed because only two studies were included. Regarding taste alteration and taste loss (Fig. 4B), a Begg's test revealed no publication bias, but an Egger's test revealed significant publication bias.

\section{Discussion}

This meta-analysis study evaluated OM, aGVHD and adverse events after HSCT in the patients undergoing palifermin compared with placebo. The results showed that palifermin had no effect on the incidence of $\mathrm{OM}$ and aGVHD. Although only the prevalence of erythema was significantly more in palifermin group, totally the incidence of the adverse events was significantly more in palifermin group compared with placebo. The common side events, 


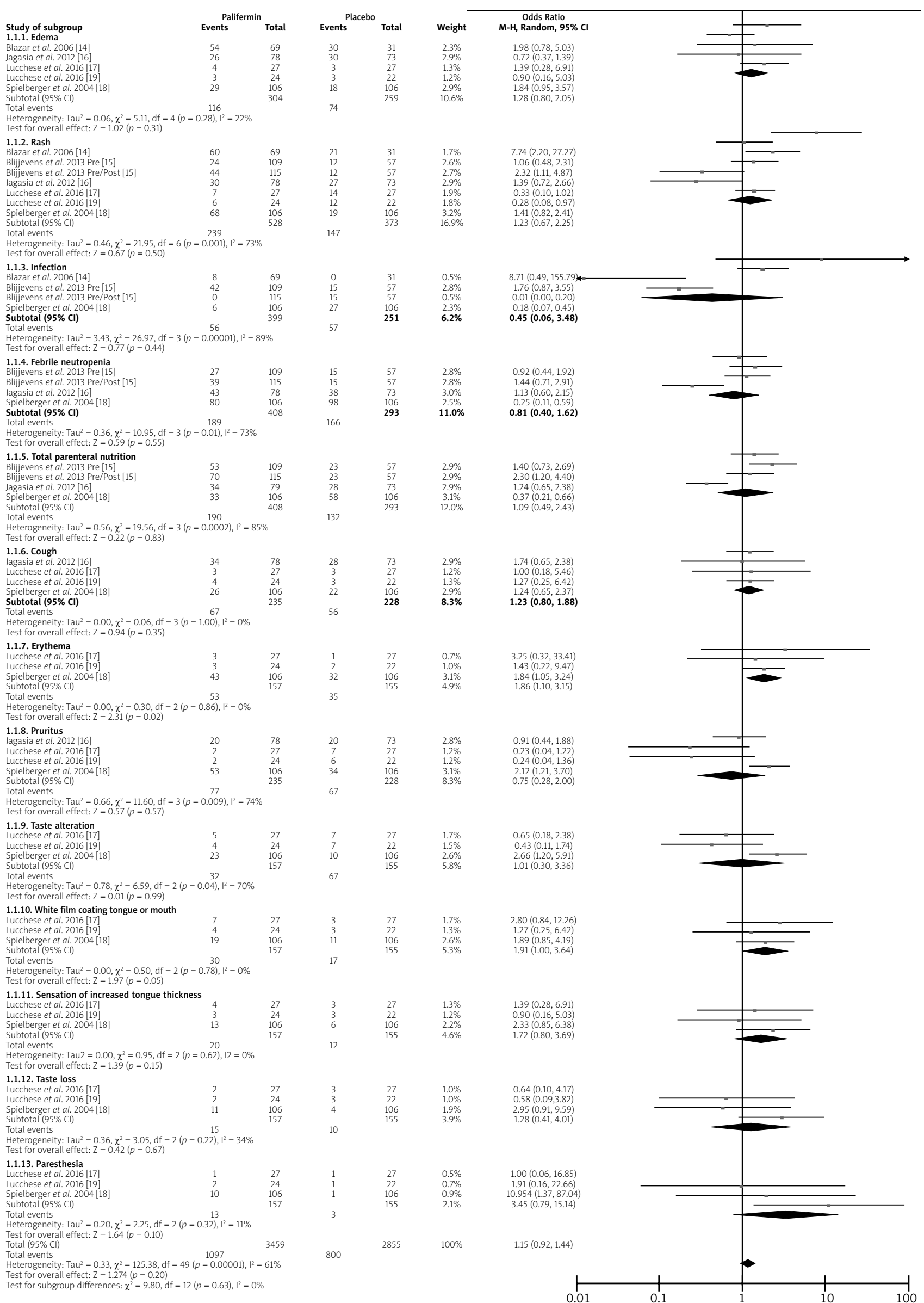

Fig. 3. Forest plot of the prevalence of adverse events after HSCT 
A

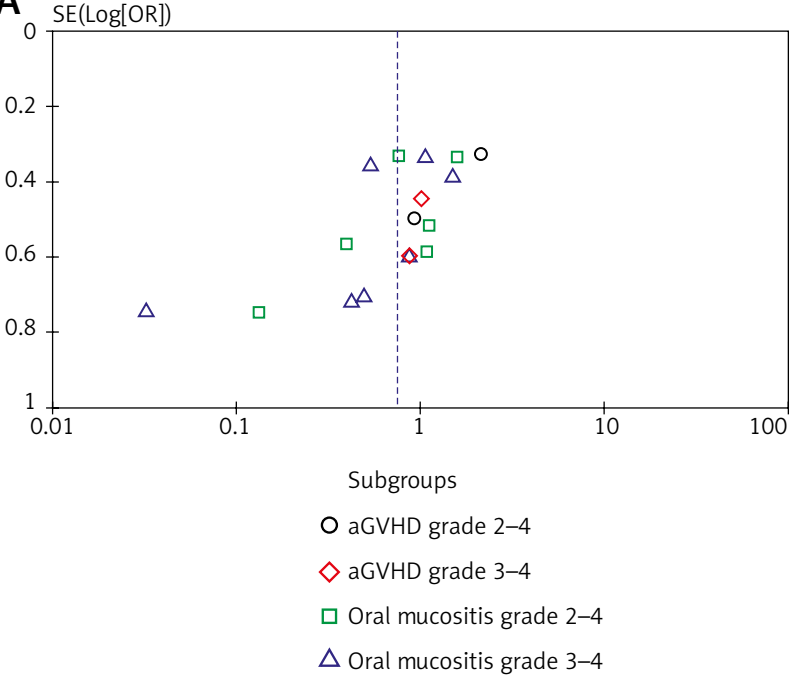

B

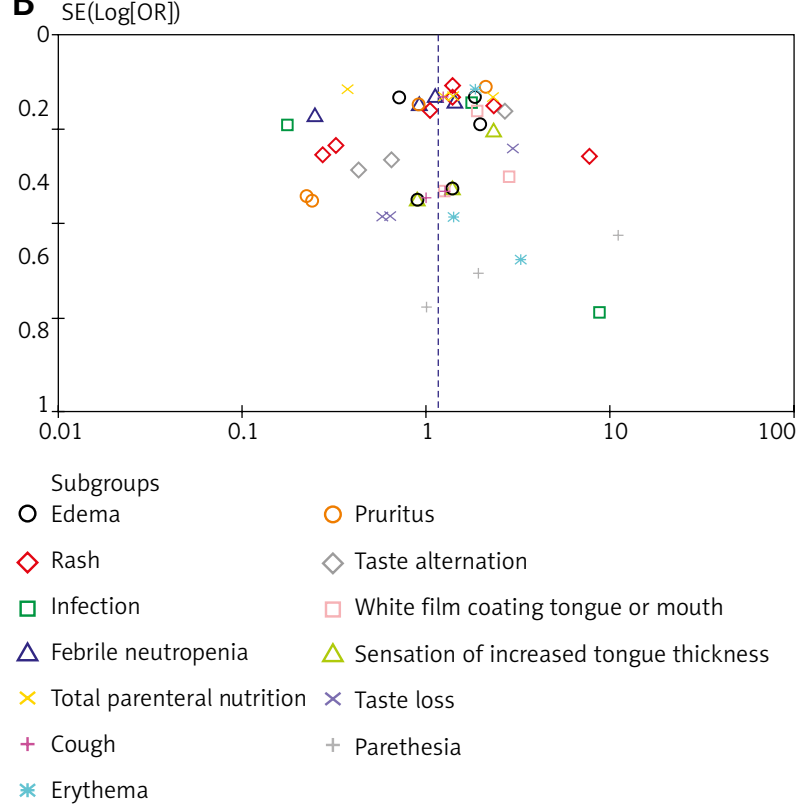

Fig. 4. The funnel plot of (A) oral mucositis and acute GVHD grades, (B) the prevalence of adverse events after HSCT

which have been noted with palifermin included a white coating of the tongue, rash, edema and elevated amylase and lipase [18-22], whereas this study showed that erythema can be an another common side event from palifermin.

The efficacy of palifermin has been established in a number of clinical trials, in which it was shown to reduce significantly the duration, incidence, and severity of OM after intensive chemotherapy and radiotherapy for HMs [23]. The results showed that in patients with hematologic cancers who were undergoing auto-HSCT after total-body irradiation (TBI) and high-dose chemotherapy, the incidence of grade 4 OM was more significantly reduced with palifermin than with placebo and also the incidence of grade 3-4 OM was $98 \%$ in the control group versus $63 \%$ in the palifermin group [18]. A retrospective study on 251 patients undergoing allo-HSCT that 154 of whom received peritransplant palifermin, the efficacy of palifermin was only significant in patients who received a TBI-, but not busulfan-based chemotherapy conditioning regimen and also the results showed that palifermin did not effect on GVHD [24]. One RCT study [16] evaluated the efficacy of palifermin after myeloablation and allo-HSCT. One group received palifermin $60 \mu \mathrm{g} / \mathrm{kg} /$ day for three consecutive days before conditioning and a single dose of $180 \mathrm{mg} / \mathrm{kg}$ after TBI and another group received methotrexate (plus cyclosporine A or tacrolimus). The incidence and severity of aGVHD were similar between treatment groups compared to placebo groups. The most commonly reported treatment-related adverse events were rash, pruritus and erythema. Another RCT study [14], investigated various dosing regimens of palifermin in allo-HSCT and concluded there were no significant differences in the incidence and severity of aGVHD between the palifermin and placebo groups, but palifermin was associated with reduced incidence and severity of mucositis (measured three times weekly), but only in patients conditioned with fractionated TBI-based regimens. Therefore, palifermin protection from lethality and organ tissue injury varies with the conditioning regimen and intensity [25] and it is important that palifermin given prior to TBI-based regimens in rodents improved thymopoiesis and peripheral immune reconstitution, likely via effects on thymic epithelial cells [26, 27].

The case-control study of Nasilowska-Adamska et al. [28] evaluated the role of palifermin in the prevention during auto- or allo-HSCT and after conditioning regimens. A significant reduction was noted in the incidence of $O M$ and $\mathrm{aGVHD}$ in the palifermin group compared to the control group [28]. Langner et al. [29] reported the incidence of grades 2-4 OM was significantly less than the control group, whereas in grades 3-4 was not significant between two groups and palifermin had no effect on the incidence and severity of aGVHD. One RCT study checked the efficacy of palifermin in acute lymphoblastic leukemia pediatric patients. During auto-HSCT therapy, patients in the palifermin group were randomly assigned to receive palifermin, $60 \mu \mathrm{g} / \mathrm{kg} /$ day, intravenously as a single dose 3 days before auto-HSCT infusion. There was a statistically significant reduction in the incidence of grade 3-4 OM in the palifermin group compared with the control group [17]. In a high-dose melphalan setting after auto-HSCT, palifermin was unable to reduce OM in MM transplant patients [15].

The trials showed the benefits of palifermin after HSCT in patients with HMs that received TBI-based conditioning regimens, but didn't show for the patients receiving non-TBI based regimens. The meta-analysis showed that a dose of $60 \mu \mathrm{g} / \mathrm{kg} /$ day of palifermin can't be effective in all patients and the clinicians should pay attention to the types of HSCT, regimen, and malignancy in the patients undergoing palifermin therapy. Also, the higher incidence and severity of OM or aGVHD and also differences in the prevalence of adverse events in some RCTs may be due to the difference in conditioning regimens or HSCT used or type of HM. Limitations of this meta-analysis were: 1) The adverse events reported in the studies after HSCT were 
not similar. 2) All studies didn't report the incidence and severity of all aGVHD or OM grades. 3) Type of chemotherapy and type of HSCT were different in the studies. 4) One study used two doses of palifermin in the patients. 5) One study did palifermin therapy in two types of courses (pre-/ post-HDM and pre-HDM).

In conclusion, this meta-analysis of six clinical trials found no statistically a significant difference in $\mathrm{OM}$ and aGVHD grades in patients receiving $60 \mu \mathrm{g} / \mathrm{kg} /$ day dose of palifermin compared with those receiving a placebo. However, oral mucosal erythema was more prevalent among patients receiving palifermin than patients receiving a placebo.

\section{The authors declare no conflict of interest.}

\section{References}

1. Bellm LA, Epstein JB, Rose-Ped A, Martin P, Fuchs HJ. Patient reports of complications of bone marrow transplantation. Support Care Cancer 2000; 8: 33-9.

2. Peterson DE, Cariello A. Mucosal damage: a major risk factor for severe complications after cytotoxic therapy. Semin Oncol 2004; 31: $35-44$.

3. Cutler C, Li S, Kim HT, et al. Mucositis after hematopoietic stem cell transplantation: a cohort study of methotrexate- and nonmethotrexate-containing graft-versus-host disease prophylaxis regimens. Biol Blood Marrow Transplant 2005; 11: 383-8.

4. Gabriel DA, Shea T, Olajida O, Serody JS, Comeau T. The effect of oral mucositis on morbidity and mortality in bone marrow trans plant. Semin Oncol 2003; 30: 76-83.

5. Lark RL, McNeil SA, VanderHyde K, Noorani Z, Uberti J, Chenoweth C. Risk factors for anaerobic bloodstream infections in bone marrow transplant recipients. Clin Infect Dis 2001; 33: 338-43.

6. McGuire DB, Rubenstein EB, Peterson DE. Evidence-based guidelines for managing mucositis. Sem Oncol Nurs 2004; 20: 59-66.

7. Dodd MJ. The pathogenesis and characterization of oral mucositis associated with cancer therapy. Oncol Nurs Forum 2004; 31: 5-11.

8. Farrell CL, Rex KL, Chen JN. The effects of keratinocyte growth factor in preclinical models of mucositis. Cell Prolif 2002; 35: S78-S85.

9. Brosa M, Arocho R. Cost-effectiveness of the prevention of oral mucositis (OM) with Kepivance ${ }^{\circledR}$ (palifermin) in patients undergoing myeloablative therapy with autologous stem cell transplantation (ASCT) in Spain. Value in Health 2006; 9: A282.

10. Przepiorka D, Weisdorf D, Martin P, et al. 1994 Consensus Conference on Acute GVHD Grading. Bone Marrow Transplant 1995; 15: 825-8.

11. Okada EM, Ribeiro LN, Stuani MB, et al. Effects of chlorhexidine varnish on caries during orthodontic treatment: a systematic review and meta-analysis. Braz Oral Res 2016; 30: e115.

12. Fowkes FG, Fulton PM. Critical appraisal of published research: introductory guidelines. BMJ 1991; 302: 1136-40.

13. Egger M, Smith G, Schneider M, Minder C. Bias in meta-analysis detected by a simple, graphical test. BMJ 1997; 315: 629-34.

14. Blazar BR, Weisdorf DJ, Defor T, et al. Phase 1/2 randomized, placebo-control trial of palifermin to prevent graft-versus-host disease (GVHD) after allogeneic hematopoietic stem cell transplantation (HSCT). Blood 2006; 108: 3216-22.

15. Blijlevens N, de Château M, Krivan G, et al. In a high-dose melphalan setting, palifermin compared with placebo had no effect on oral mucositis or related patient's burden. Bone Marrow Transplant 2013; 48: 966-71.

16. Jagasia MH, Abonour R, Long GD, et al. Palifermin for the reduction of acute GVHD: a randomized, double-blind, placebo-controlled trial. Bone Marrow Transplant 2012; 47: 1350-5.

17. Lucchese A, Matarese G, Ghislanzoni LH, Gastaldi G, Manuelli M, Gherlone E. Efficacy and effects of palifermin for the treatment of oral mucositis in patients affected by acute lymphoblastic leukemia. Leuk Lymphoma 2016; 57: 820-7.

18. Spielberger R, Stiff P, Bensinger W, et al. Palifermin for oral mucositis after intensive therapy for hematologic cancers. N Engl I Med 2004; 351: 2590-8.

19. Lucchese A, Matarese G, Manuelli M, et al. Reliability and efficacy of palifermin in prevention and management of oral mucositis in patients with acute lymphoblastic leukemia: a randomized, double-blind controlled clinical trial. Minerva Stomatol 2016; 65: 4350.

20. Blijlevens N, Sonis S. Palifermin (recombinant keratinocyte growth factor-1): a pleiotropic growth factor with multiple biological activities in preventing chemotherapy- and radiotherapy-induced mucositis. Ann Oncol 2007; 18: 817-26.

21. Meropol NJ, Somer RA, Gutheil J, et al. Randomized phase I trial of recombinant human keratinocyte growth factor plus chemotherapy: potential role as mucosal protectant. J Clin Oncol 2003; 21: $1452-8$

22. Abidi MH, Agarwal R, Tageja N, et al. A phase I dose-escalation trial of high-dose melphalan with palifermin for cytoprotection followed by slogous stem cell transplantation for patients with multiple myeloma with normal renal function. Biol Blood Marrow Transplant 2013; 19: 56-61.

23. Fliedner M, Baguet B, Blankart J, et al. Palifermin for patients with haematological malignancies: shifting nursing practice from symptom relief to prevention of oral mucositis. Eur J Oncol Nurs 2007; 11: S19-26.

24. Goldberg JD, Zheng J, Castro-Malaspina $\mathrm{H}$, et al. Palifermin is efficacious in recipients of TBI-based but not chemotherapy-based allogeneic hematopoietic stem cell transplants. Bone Marrow Transplant 2013; 48: 99-104.

25. Panoskaltsis-Mortari A, Lacey DL, Vallera DA, et al. Keratinocyte growth factor administered before conditioning ameliorates graftversus-host disease after allogeneic bone marrow transplantation in mice. Blood 1998: 92: 3960-7.

26. Alpdogan O, Hubbard VM, Smith OM, et al. Keratinocyte growth factor (KGF) is required for postnatal thymic regeneration. Blood 2006; 107: 2453-60.

27. Rossi S, Blazar BR, Farrell CL, et al. Keratinocyte growth factor preserves normal thymopoiesis and thymic microenvironment during experimental graft versus-host disease. Blood 2002; 100: 682-91.

28. Nasilowska-Adamska B, Rzepecki P, Manko J, et al. The influence of palifermin (Kepivance) on oral mucositis and acute graft versus host disease in patients with hematological diseases undergoing hematopoietic stem cell transplant. Bone Marrow Transplant 2007; 40: 983-8

29. Langner S, Staber P, Schub N, et al. Palifermin reduces incidence and severity of oral mucositis in allogeneic stem-cell transplant recipients. Bone Marrow Transplant 2008; 42: 275-9.

\section{Address for correspondence}

\section{Masoud Sadeghi}

Medical Biology Research Center

Kermanshah University of Medical Sciences

Kermanshah, Iran

tel. +989185960644

$\mathrm{fax}+988334276471$

e-mail: sadeghi_mbrc@yahoo.com

Submitted: 8.06 .2017

Accepted: 27.07 .2017 